\title{
Article \\ Anti-Inflammatory Effects of Novel Glycyrrhiza Variety Wongam In Vivo and In Vitro
}

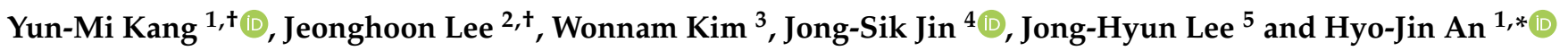 \\ 1 Department of Pharmacology, College of Korean Medicine, Sangji University, 83 Sangjidae-gil, \\ Wonju 26339, Gangwon-do, Korea; yunmi6115@naver.com \\ 2 Herbal Crop Research Division, National Institue of Horticultural and Herbal Science, Rural Development \\ Administration, 92 Bisan-ro, Eumseong 27709, Chungbuk, Korea; artemisia@korea.kr \\ 3 Cnh Center for Cancer Research, 462 Bongeunsa-ro, Seoul 06154, Gangnam-gu, Korea; eb75lab@gmail.com \\ 4 Department of Oriental Medicine Resources, Jeonbuk National University, 79 Gobong-ro, \\ Iksan 54596, Jeollabuk-do, Korea; jongsik.jin@jbnu.ac.kr \\ 5 Department of Pharmacy, College of Pharmacy, Dongduk Women's University, 60 Hwarang-ro 13-gil, \\ Seoul 02748, Seongbuk-gu, Korea; naturalmed@dongduk.ac.kr \\ * Correspondence: sangjipharm@gmail.com; Tel.: +82-33-738-7503 \\ + These authors equally contributed to this research work and should be considered co-first authors.
}

Citation: Kang, Y.-M.; Lee, J.; Kim, W.; Jin, J.-S.; Lee, J.-H.; An, H.-J.

Anti-Inflammatory Effects of Novel Glycyrrhiza Variety Wongam In Vivo and In Vitro. Appl. Sci. 2021, 11, 10822 https://doi.org/10.3390/ app112210822

Academic Editor: Antony C. Calokerinos

Received: 14 October 2021

Accepted: 15 November 2021

Published: 16 November 2021

Publisher's Note: MDPI stays neutral with regard to jurisdictional claims in published maps and institutional affiliations.

Copyright: () 2021 by the authors. Licensee MDPI, Basel, Switzerland. This article is an open access article distributed under the terms and conditions of the Creative Commons Attribution (CC BY) license (https:// creativecommons.org/licenses/by/ $4.0 /)$.

\begin{abstract}
Licorice is the common name of Glycyrrhiza species, which is an important plant for edible and medicinal purposes; however, Glycyrrhiza resources have become limited because of desertification, depletion of natural resources, and environmental restrictions. For this reason, a novel Glycyrrhiza variety named Wongam, a hybrid of G. glabra and G. uralensis, was developed by the Korea Rural Development Administration. To elucidate the antiallergic inflammatory effects of Wongam, we investigated its effects using a compound-48/80-induced anaphylaxis in vivo model and PMA/A23187-stimulated HMC-1 cells and immunoglobulin E (IgE)/DNP-stimulated RBL-2H3 cells in in vitro models. Wongam treatment reduced mortality and serum IgE levels and downregulated proinflammatory cytokines and chemokines in a compound-48/80-induced anaphylaxis mouse model. Wongam decreased histamine release and the expression of proinflammatory cytokines in HMC-1 and RBL-2H3 cells. Wongam treatment downregulated the expression of chemokines, T helper 2 cytokines, and cell surface antigens in PMA/A23187-stimulated HMC-1 cells. We confirmed that these effects were associated with the inhibition of the MAPK and NF- $\mathrm{KB}$ signaling pathways by Wongam. The present study suggests that Wongam ameliorates mast-cell-mediated allergic inflammatory responses by reducing mast cell activation and may serve as an effective agent for the prevention and treatment of allergic inflammatory responses.
\end{abstract}

Keywords: allergy; inflammation; novel Glycyrrhiza varieties; Wongam; mast cell activation; anaphylaxis

\section{Introduction}

Licorice, the common name of the Glycyrrhiza species, is widely used as a natural sweetener and in cosmetics and herbal medicine. Although licorice is an essential herbal medicine in Korea, it is mostly imported. However, there are urgent problems related to the supply instability caused by the serious desertification of Central Asia, the consequent depletion of natural resources, and agricultural problems such as low productivity. To solve these problems, a novel Glycyrrhiza variety named Wongam (Glycyrrhiza korshinskyi Grig.) was developed by the Korea Rural Development Administration. Wongam is a hybrid of G. glabra and G. uralensis, which improves the defects of the original licorice strains, such as their low yield and insufficient contents of the main components. Our research group has been investigating the properties, homogeneity, and pharmacological effects of Wongam with registered Glycyrrhiza species in official compendia, and has reported on the safety of Wongam in terms of general toxicity [1], genotoxicity [2], and its antiulcerative colitis activity [3] in order to extend the utilization of the novel Glycyrrhiza variety. Licorice has been 
extensively used to treat coughs, gastritis, peptic ulcers, respiratory infections, and arthritis for many centuries [4]. Many studies have shown that the original Glycyrrhiza species and their components have a number of pharmacological effects, including antiallergic [5], anti-inflammatory [6], antiasthmatic [7], antiviral [8], antitumor [9], and antidepressant activities [10]. To utilize Wongam as a medicinal plant with the original Glycyrrhiza species, the efficacy of original Glycyrrhiza species compared with Wongam should be investigated. In this study, we focused on the role of Wongam in allergic inflammatory responses.

An allergic response is a hypersensitive immune reaction that occurs in response to an allergen or antigen. Approximately $10-40 \%$ of each country's population is affected by allergies, with a significant annual increase in allergy patients [11]. A number of reports have highlighted elevated immunoglobulin E (IgE) levels in patients suffering from allergies [12]. Mast cells are well recognized as being essential in the pathogenesis of allergic responses and inflammation. Through the high-affinity IgE receptor (FceRI) binding, IgE mediates mast cell activation, leading to degranulation and release of biologically active products, such as histamine and tryptase [13]. T helper (Th) 2 cells, upon stimulation by antigens, produce the prototypical type 2 cytokines such as interleukin (IL)- 4 and IL-13, which are required for B-cell activation, IgE production, and switching to mast cell activation [14]. Following aggregation of FceRI, cell surface antigen CD63 and CD203c expression is upregulated, resulting in their overexpression on basophils and mast cells, implicating them in cell activation and some allergic diseases $[15,16]$. Anaphylaxis, a severe allergic reaction, is a potentially life-threatening, rapidly progressing systemic hypersensitivity reaction, which often follows exposure to small amounts of allergens, including insect venom, foods, and medications. IgE antibodies, effector mast cells, basophils, the mediator histamine, and leukotrienes are responsible for most anaphylactic events. However, anaphylaxis also induces changes in other mediators, including tryptase, prostaglandins, cytokines, and chemokines [17].

We hypothesized that the novel Glycyrrhiza variety Wongam would exert antiallergic effects because of a single Glycyrrhiza species (such as G. glabra and G. uralensis) and because its components have well-known effects against allergies. These promising effects motivated us to explore the mechanisms of action of Wongam as an antiallergic agent without adverse effects. This is the first study aiming to investigate the antiallergic effects of Wongam extract (WG) in vivo and in vitro. To elucidate the antiallergic effects of Wongam, we used an in vivo compound-48/80-induced anaphylaxis mouse model and in vitro RBL$2 \mathrm{H} 3$ and HMC-1 cells. The results showed that WG can ameliorate allergic markers by regulating mast-cell-mediated allergic responses.

\section{Materials and Methods}

\subsection{Chemicals and Reagents}

In the present study, disodium cromoglycate (DSCG), 3-(4,5-Dimethylthiazol-2-yl)-2, 5diphenyl tetrazolium bromide (MTT), 3-(4,5-dimethylthiazol-2-yl)-5-(3-carboxymethoxyphenyl)2-(4-sulfophenyl)-2H-tetrazolium (MTS), calcium ionophore A23187 (Calcimycin), phorbol 12-myristate 13-acetate (PMA), antidinitrophenyl immunoglobulin E (anti-DNP IgE), dinitrophenyl human serum albumin (DNP-HAS), dimethyl sulfoxide (DMSO), and all other chemicals were obtained from Millipore Sigma (Billerica, MA, USA). Fetal bovine serum (FBS), Iscove's modified Dulbecco's medium (IMDM), Dulbecco's modified Eagle's medium (DMEM), penicillin, and streptomycin were purchased from Life Technologies, Inc. (Grand Island, NY, USA). Primary antibodies against phospho-IKB kinase (IKK) $\alpha / \beta$ (cat no. 2697, monoclonal), extracellular signal-regulated kinase (ERK) (cat no. 9102, polyclonal), p-ERK (cat no. 9101, polyclonal), c-Jun N-terminal kinase (JNK) (cat no. 9252, polyclonal), and pJNK (cat no. 9251, polyclonal) were obtained from Cell Signaling Technology, Inc. (Danvers,

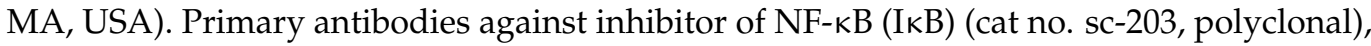
IKK $\alpha / \beta$ (cat no. sc-7607, polyclonal), and $\beta$-actin (cat no. sc-81178, monoclonal) were obtained from Santa Cruz Biotechnology, Inc. (Dallas, TX, USA). Horseradish peroxidase (HRP) secondary antibodies were purchased from Jackson ImmunoResearch Laboratories, 
Inc. (West Grove, PA, USA). The histamine ELISA kit was purchased from Enzo Life Sciences, Inc. (Farmingdale, NY, USA). ELISA kits for IgE tumor necrosis factor (TNF)- $\alpha$ and interleukin (IL)-6 were obtained from R\&D Systems, Inc. (Minneapolis, MN, USA). SYBR Premix Ex Taq was purchased from Takara Bio, Inc. (Shiga, Japan). The oligonucleotide primers were purchased from Bioneer Corporation (Daejeon, Korea).

\subsection{Sample Preparation}

WG was provided by the Korea Rural Development Administration and identified by Dr. Jeonghoon Lee (RDA, Korea). The sample was extracted with water (100 g/L) for $3 \mathrm{~h}$ and concentrated under reduced pressure using a rotary evaporator at temperature of $40-45^{\circ} \mathrm{C}$. The decoction was filtered, lyophilized, and then stored at $4{ }^{\circ} \mathrm{C}$. The yield of the dried extract from the starting crude material WG was $8.8 \%$. The resulting extract powder was dissolved in distilled water for study.

\subsection{Compound-48/80-Induced Anaphylactic Shock Model}

A total of 24 male ICR mice ( 6 weeks old; $25-28$ g body weight) were obtained from Charles River Laboratories (Harlan Laboratories, Inc., Wilmington, MA, USA) and housed under constant conditions at a humidity of $40-60 \%$, temperature of $20-25^{\circ} \mathrm{C}$, and a $12 \mathrm{~h}$ light/dark cycle. The mice were randomly assigned to one of four groups $(n=6$ per group). Systemic anaphylactic shock was induced with compound 48/80 as described previously [18]; briefly, ICR mice were injected intraperitoneally (i.p.) with phosphatebuffered saline (PBS) or compound 48/80 dissolved in PBS. Then, WG (100 mg/kg), DSCG $(25 \mathrm{mg} / \mathrm{kg})$, or PBS was dissolved in saline and injected i.p. for $1 \mathrm{~h}$ prior to the compound $48 / 80$ injection. The concentration and administration route of WG were determined in reference to previous studies $[3,19,20]$. The survival of mice was monitored for $1 \mathrm{~h}$ following the anaphylactic shock induction. The obtained survival data were analyzed using the Kaplan-Meier method and log rank test. Blood was collected from the heart of each mouse to measure serum cytokine profiles. After collection of the whole blood, the blood was allowed to clot for $1 \mathrm{~h}$ at room temperature and then centrifuged for $20 \mathrm{~min}$ at $3000 \times g$ and $4{ }^{\circ} \mathrm{C}$ to obtain serum. Mice were sacrificed by cervical dislocation. All procedures were performed in accordance with the university guidelines and approved by the Ethical Committee for Animal Care and the Use of Laboratory Animals, Korean Medicine, Sangji University (Wonju, South Korea; approval no. 2019-10).

\subsection{IgE and Cytokine Assays}

Blood serum was obtained by centrifugation at $1700 \times g$ for $30 \mathrm{~min}$ and stored at $-80{ }^{\circ} \mathrm{C}$ until analysis. The levels of TNF- $\alpha$, IL-6, and IgE were measured using ELISA kits according to the respective manufacturers' protocols.

\subsection{Reverse Transcription-Quantitative Polymerase Chain Reaction Analysis}

Total RNA was extracted from cells or liver tissues using an Easy Blue kit (Intron Biotechnology, Inc., Seoul, Korea) according to the manufacturer's protocol. RNA was quantified using an Epoch microplate spectrophotometer system (BioTek Instruments, Inc., Winooski, VT, USA). Here, cDNA was obtained using d(T)16 primer, isolated total RNA $(2 \mu \mathrm{g})$, and Avian Myeloblastosis Virus reverse transcriptase with genomic DNA remover. Relative gene expression was quantified using a Real-Time PCR System 7500 (Applied Biosystems; Thermo Fisher Scientific, Inc., Waltham, MA, USA) with SYBR Premix Ex Taq. Fold changes in gene expression were calculated using the comparative quantification cycle method. The $\mathrm{Cq}$ values of target genes were normalized to that of GAPDH using the ABI Gene Express 2.0 program (Applied Biosystems; Thermo Fisher Scientific, Inc., Waltham, MA, USA). 


\subsection{HMC-1 Cell Culture and WG Treatment}

HMC-1 cells were provided by Professor Jong-Sik Jin (Jeonbuk University, Republic of Korea) and were grown at $37^{\circ} \mathrm{C}$ in IMDM supplemented with penicillin $(100 \mathrm{U} / \mathrm{mL})$, streptomycin $(100 \mu \mathrm{g} / \mathrm{mL})$, and $10 \% \mathrm{FBS}$ in a humidified atmosphere with $5 \% \mathrm{CO}_{2}$. HMC-1 cells were seeded $\left(1 \times 10^{6}\right.$ cells per well $)$ and treated with WG for $30 \mathrm{~min}$ at $37^{\circ} \mathrm{C}$ in humidified air with $5 \% \mathrm{CO}_{2}$ and then stimulated with $40 \mathrm{nM}$ PMA and $1 \mu \mathrm{M}$ A23187 (PMACI).

\subsection{RBL-2H3 Cell Sensitization and Stimulation}

RBL-2H3 was purchased from the Korea Cell Line Bank (KCLB, Seoul, Republic of Korea). The cells were grown at $37^{\circ} \mathrm{C}$ in DMEM supplemented with penicillin $(100 \mathrm{U} / \mathrm{mL})$, streptomycin $(100 \mu \mathrm{g} / \mathrm{mL})$, and $10 \%$ FBS in a humidified atmosphere of $5 \% \mathrm{CO}_{2}$. RBL-2H3 cells were seeded $\left(1 \times 10^{5}\right.$ cells per well $)$ and incubated with $50 \mathrm{ng} / \mathrm{mL}$ of anti-DNP-IgE overnight for cell sensitization. After washing with PBS three times, the cells were exposed to WG for $1 \mathrm{~h}$ and then stimulated with $100 \mathrm{ng} / \mathrm{mL}$ of DNP-HAS for $4 \mathrm{~h}$.

\subsection{Cell Viability Assay}

Cells were seeded $\left(5 \times 10^{4}\right.$ per well) in a 96-well culture plate. The cells were treated with medium containing various concentrations of WG. After incubation for $4 \mathrm{~h}$, the cells were treated with $20 \mu \mathrm{L}$ of MTS for $4 \mathrm{~h}$, and absorbance (at $490 \mathrm{~nm}$ ) was measured using a microplate reader. After incubation for $24 \mathrm{~h}, \mathrm{RBL}-2 \mathrm{H} 3$ cells were treated with $50 \mu \mathrm{L}$ of MTT $(5 \mu \mathrm{g} / \mathrm{mL})$ for $4 \mathrm{~h}$. The formazan precipitate was dissolved in DMSO and the absorbance (at $540 \mathrm{~nm}$ ) was measured using a microplate reader.

\subsection{Histamine Assay}

Culture media were collected after treatment with WG and stored at $-80^{\circ} \mathrm{C}$. Histamine levels were measured in the culture supernatants using ELISA kits according to the manufacturer's protocol.

\subsection{Western Blot Analysis}

Cells and liver tissue samples were suspended in PROPREP ${ }^{\mathrm{TM}}$ protein extraction solution (Intron Biotechnology, Inc., Seoul, Korea) and incubated for $20 \mathrm{~min}$ at $4{ }^{\circ} \mathrm{C}$. Cell debris was removed via microcentrifugation at $11,000 \times \mathrm{g}$ for $30 \mathrm{~min}$ at $4{ }^{\circ} \mathrm{C}$, followed by rapid freezing of the supernatant. Protein concentrations were quantified using the Bio-Rad protein assay reagent (Bio-Rad Laboratories, Inc., Hercules, CA, USA) according to the manufacturer's protocol. Proteins were electroblotted onto a polyvinylidene fluoride membrane following separation via $8-12 \%$ SDS-PAGE. The membrane was incubated for 30 min with blocking solution ( $5 \%$ skim milk) at room temperature, followed by overnight incubation with primary antibodies $(1: 1000)$ at $4{ }^{\circ} \mathrm{C}$. The blots were washed three times with Tween 20/Tris-buffered saline (T/TBS) and incubated with horseradish-peroxidaseconjugated secondary antibody (1:2500) for $2 \mathrm{~h}$ at room temperature. The blots were washed three times with T/TBS and then developed via enhanced chemiluminescence (GE Healthcare Life Sciences, Chalfont, UK). Densitometric analysis was performed using Bio-Rad Quantity One software (version 4.3.0; Bio-Rad Laboratories Inc.).

\subsection{Statistical Analysis}

Data are expressed as means \pm standard deviations of triplicate experiments. Statistically significant differences were compared using one-way analysis of variance and Dunnett's post hoc test. Differences were considered statistically significant at $p<0.05$. Statistical analysis was performed using SPSS statistical analysis software (version 19.0, IBM SPSS, Armonk, NY, USA). 


\section{Results}

\subsection{WG Protects against Mortality and Decreases IgE Levels in Compound-48/80-Induced Anaphylactic Shock Mice Model}

To investigate the effects of WG on allergic responses, we designed a mast cell stimulator compound-48/80-induced anaphylaxis mouse model. We observed the survival rate of mice with compound-48/80-induced systemic anaphylaxis. The results showed that intraperitoneal (i.p.) injection of compound $48 / 80$ decreased the survival rate within $30 \mathrm{~min}$. However, when mice were pretreated with WG at a dose of $100 \mathrm{mg} / \mathrm{kg}$ for $1 \mathrm{~h}$ before administration of compound $48 / 80$, the mortality was reduced (Figure $1 \mathrm{~A}$ ). To determine whether WG inhibits IgE levels, we measured the serum levels of $\operatorname{IgE}$ after anaphylactic shock. WG administration significantly decreased the compound-48/80-induced serum IgE levels (Figure 1B).

A

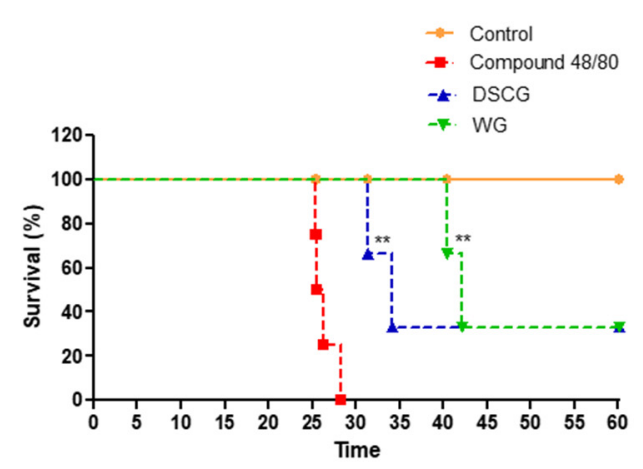

$\mathrm{C}$

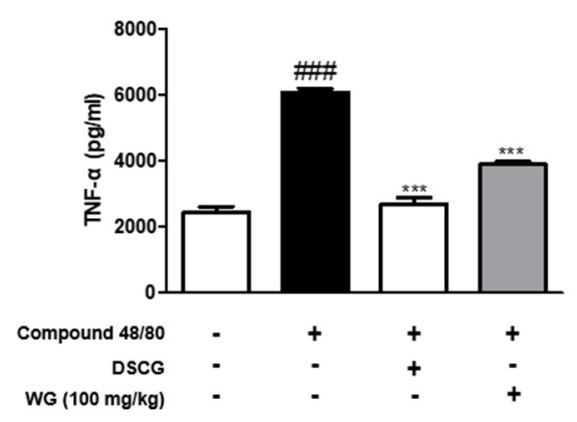

$\mathrm{B}$

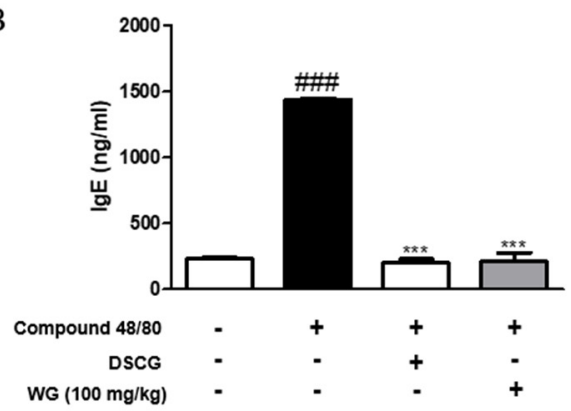

$\mathrm{D}$

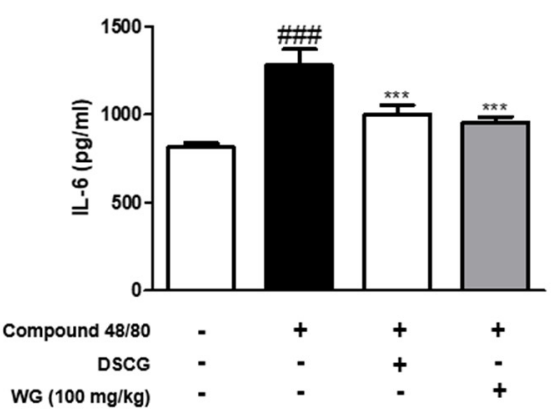

Figure 1. Effects of WG on compound-48/80-induced mortality and inflammatory cytokine production in anaphylaxis shock animal model. (A) Survival rates of mice were monitored for $1 \mathrm{~h}$. (B) IgE serum levels were measured using ELISA kit. (C) TNF- $\alpha$ and (D) IL-6 cytokine production from serum was measured using ELISA kit. The data shown represent means \pm S.D. of three independent experiments. Note: ${ }^{\# \#} p<0.001$ vs. the control group; ${ }^{* *} p<0.01$ and ${ }^{* * *} p<0.001$ vs. compound 48/80-treated group. DSCG; disodium cromoglycate.

\subsection{WG Inhibits the Production of ProInflammatory Cytokines and Chemokines in the Mouse} Model of Anaphylaxis

Next, we examined the serum levels of proinflammatory cytokines induced by compound 48/80 in the anaphylaxis mouse model. As shown in Figure 1C,D, injection of compound 48/80 markedly increased the serum levels of TNF- $\alpha$ and IL-6; however, WG administration significantly decreased these proinflammatory cytokines. These results are in agreement with the mRNA expression levels of TNF- $\alpha$ and IL- 6 in the liver tissue of anaphylactic mice (Figure 2A). Moreover, we measured the expression of chemokines involved in allergic diseases [17], including eotaxin, MIP-2, and MCP-1. The mRNA levels of these chemokines were elevated in the anaphylaxis mouse group compared with the control group. However, WG at a dose of $100 \mathrm{mg} / \mathrm{kg}$ significantly decreased these levels in the liver tissue of anaphylactic mice (Figure 2B). 
A

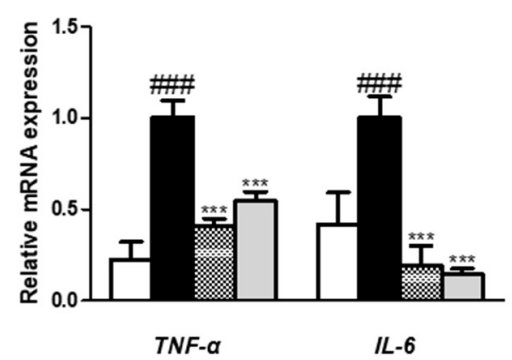

B

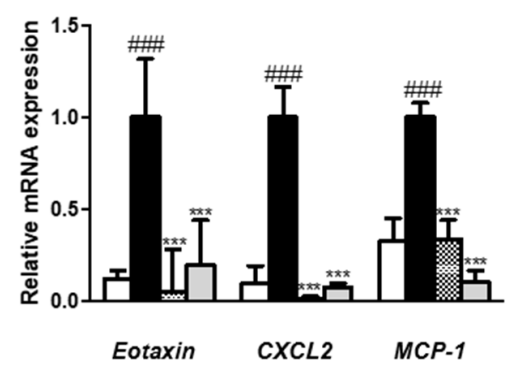

$\mathrm{C}$
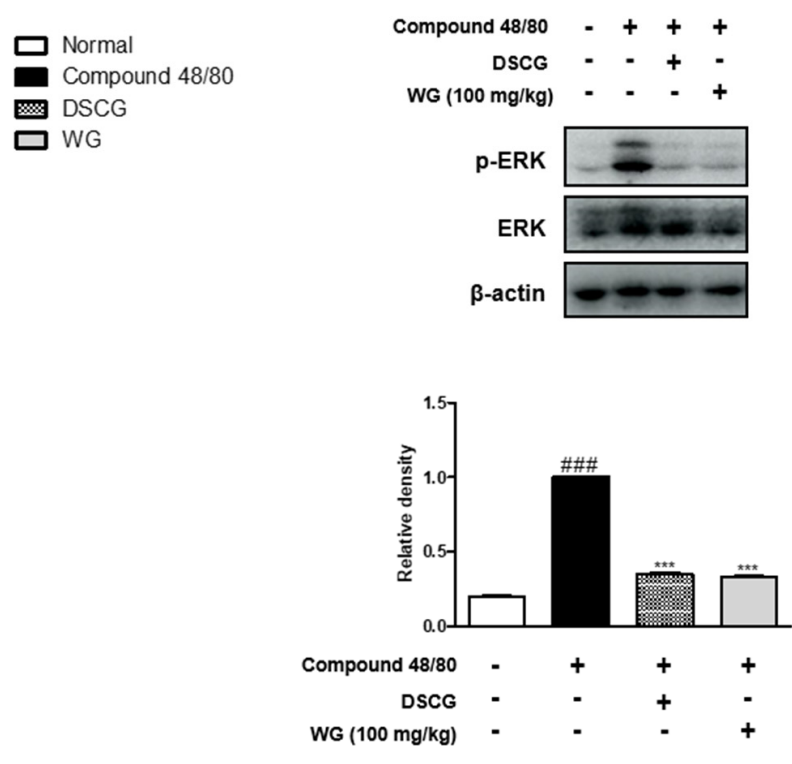

Figure 2. Effects of WG on compound-48/80-induced proinflammatory cytokines and ERK activation in a mouse model of anaphylactic shock. Total RNA prepared from the liver tissue and the mRNA levels of (A) TNF- $\alpha$, IL-6, IL-1 $\beta$, (B) Eotaxin, MIP-2, and MCP-1 were determined by quantitative qRT-PCR. (C) Expression of ERK was determined by Western blot analysis using specific antibodies. Here, $\beta$-actin was used to normalize protein expression levels. Densitometric analysis was performed using Bio-Rad Quantity One ${ }^{\circledR}$ software. The data shown represent means \pm S.D. of three independent experiments. Note: ${ }^{\# \# \#} p<0.001$ vs. the control group; ${ }^{* * *} p<0.001$ vs. compound $48 / 80$-treated group. DSCG; disodium cromoglycate.

\subsection{WG Inhibits ERK Activation in Mouse Model of Anaphylaxis}

To understand the inhibitory mechanism of WG, its inhibitory effects on mitogenactivated protein kinase (MAPK) ERK protein expression in the liver tissue of anaphylactic mice was evaluated. As shown in Figure 2C, administration of WG significantly inhibited compound-48/80-induced phosphorylation of ERK in the anaphylactic mouse model. These results indicated that WG suppressed allergic and inflammatory reactions by inhibiting mast cell degranulation, IgE synthesis, cytokine production, and ERK activation.

\subsection{WG Suppresses Mast Cell Degranulation from HMC-1 and RBL-2H3 Cells}

To verify the effect of WG on mast cells, we first measured the effects of WG on the viability of the two types of mast cell lines. HMC-1 and RBL-2H3 cells were incubated for $24 \mathrm{~h}$ with various concentrations of WG. Treatment with WG at concentrations up to $1000 \mu \mathrm{g} / \mathrm{mL}$ did not reduce cell viability (Figure 3A). Next, we tested the effects on mast cell degranulation. The mRNA expression of $\beta$-tryptase was increased by PMACI stimulation, whereas its expression was significantly downregulated by WG treatment in HMC-1 cells (Figure 3B). PMACI-stimulated HMC-1 cells and DNP-HAS-challenged RBL-2H3 cells released higher levels of histamine than the control group. WG considerably reduced histamine release in both the mast cell lines (Figure 3C,D). These results correlated with the measured serum IgE levels in vivo. 


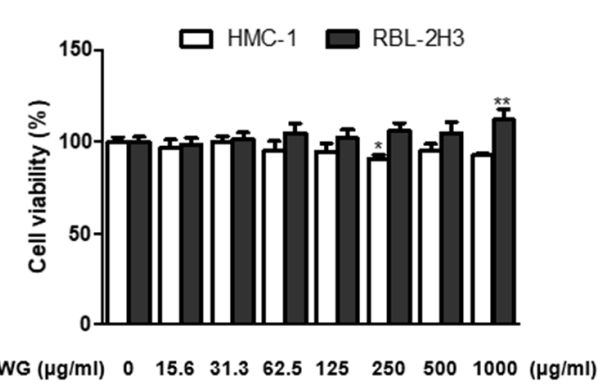

$\mathrm{C}$

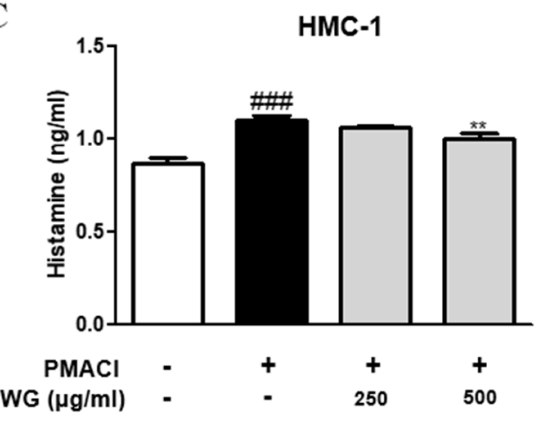

B

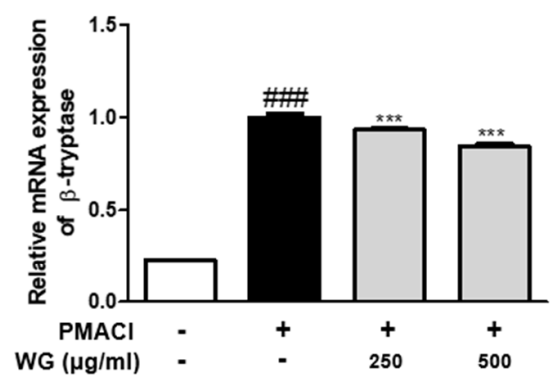

$\mathrm{D}$

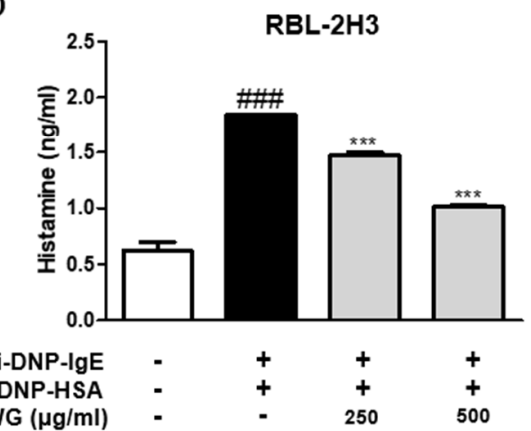

Figure 3. Effects of WG on the allergic mediators in PMACI-stimulated HMC-1 and RBL-2H3 cells. (A) HMC-1 and RBL-2H3 cells were treated with different concentrations of WG and the cell viability levels were determined using MTS/MTT assay. Note: ${ }^{*} p<0.05$ and ${ }^{* *} p<0.01$ vs. the non-treated group. (B) The mRNA level of $\beta$-tryptase was determined by quantitative qRT-PCR. $(\mathbf{C}, \mathbf{D})$ Histamine release was measured using ELISA kit. The data shown represent means \pm S.D. of three independent experiments. Note: ${ }^{\# \#} p<0.001$ vs. the control group; ${ }^{* *} p<0.01$ and ${ }^{* * *} p<0.001$ vs. stimulator-treated group.

\subsection{WG Inhibits the Expression Levels of ProInflammatory Cytokines from HMC-1 and RBL-2H3 Cells}

To determine the inhibitory effects of WG on proinflammatory cytokine production, we investigated its effects on TNF- $\alpha$ and IL-6 production and mRNA levels. PMACI significantly induced higher levels of cytokine production (Figure $4 \mathrm{~A}, \mathrm{~B}$ ) and mRNA expression (Figure 4C,D). However, these levels were decreased by pretreatment with WG in PMACI-stimulated HMC-1 cells. We obtained similar results from RBL-2H3 cells, in which DNP-HAS increased the mRNA levels of TNF- $\alpha$, IL-6, and IL- $1 \beta$, whereas WG downregulated the levels of cytokines; however, the change in IL-1 $\beta$ expression was not significant (Figure 4E). These results indicated that WG regulated the stimulator-induced expression of proinflammatory cytokines via transcriptional inhibition.

3.6. WG Downregulates the Expression Levels of Chemokines, Cell Surface Antigens, and Th2 Cytokines in PMACI-Stimulated HMC-1 Cells

Chemokines are a group of chemotactic cytokines that play a critical role in directing inflammatory cell recruitment during allergic reactions [21]. Moreover, the allergic inflammatory response is characterized by Th2 effector cell proliferation and recruitment, while Th2-related cytokines and chemokines can be found in the serum of patients suffering allergic disorders [22]; thus, we investigated the effects of WG on chemokines and Th2 cytokines. The expression levels of CC chemokines such as eotaxin, MIP-2, and MCP-1, as well as Th2 cytokines IL-4, IL-5, and IL-13, were increased by PMACI stimulation; however, these were significantly decreased by WG treatment in HMC-1 cells (Figure 5A,B). In addition to proinflammatory cytokines, several cell surface antigens, such as CD63 and CD203c, are highly relevant to an IgE-mediated allergic reaction correlating with histamine [23]. 
Our results showed that pretreatment with WG downregulated PMACI-induced CD63 and CD203c expression in HMC-1 cells (Figure 5C).

A

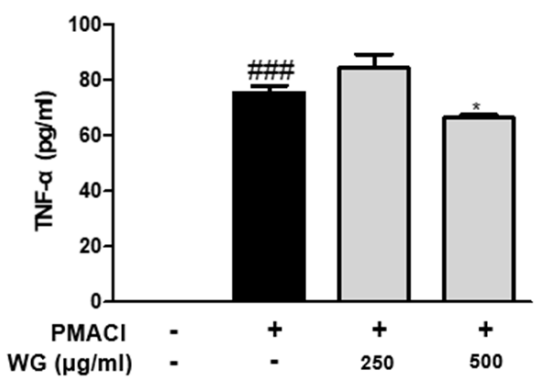

$\mathrm{C}$

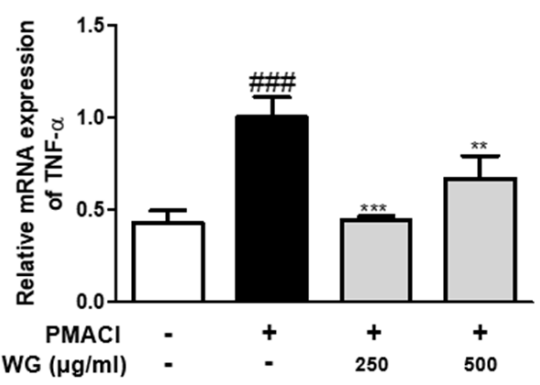

B

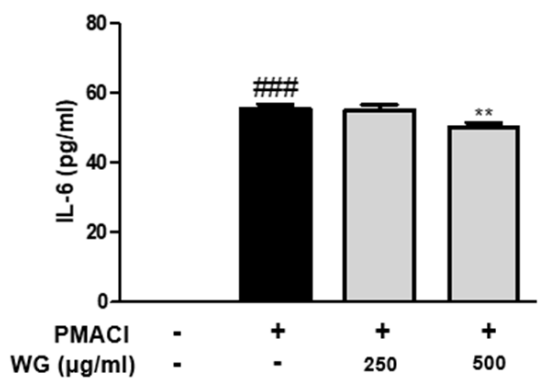

$\mathrm{D}$

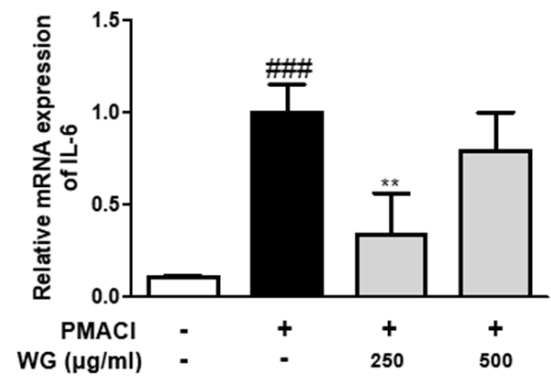

$\mathrm{E}$

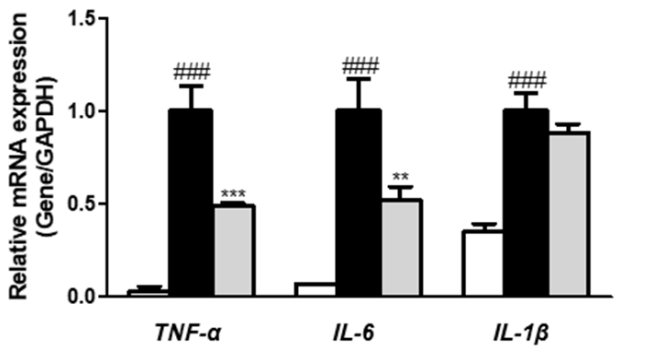

Control

Anti-DNP IgE + DNP-HSA

$\square$ Anti-DNP IgE + DNP-HSA + WG

Figure 4. Effects of WG on the proinflammatory cytokines in PMACI-stimulated HMC-1 and RBL$2 \mathrm{H} 3$ cells. (A,B) TNF- $\alpha$ and IL-6 cytokines production was measured using ELISA kit. The mRNA levels of (C) TNF- $\alpha$ and (D) IL-6 were determined by quantitative qRT-PCR from HMC-1 cells and (E) RBL-2H3 cells. The data shown represent means \pm S.D. of three independent experiments. Note: \#\#\# $p<0.001$ vs. the control group; ${ }^{*} p<0.05,{ }^{* *} p<0.01$, and ${ }^{* * *} p<0.001$ vs. stimulator-treated group.

\subsection{WG Inhibits the Activation of MAPKs and NF- $\kappa B$ Signaling Pathway in PMACI-Stimulated HMC-1 Cells}

To investigate whether WG prevents the activation of the MAPK pathway, we measured the phosphorylation levels of ERK and JNK. We found that cells pretreated with WG had significantly suppressed phosphorylation of ERK and JNK compared with those treated with PMACI alone (Figure 6A). As nuclear factor kappa B (NF-kB) is involved in cytokines, chemokines, enzymes, and key transcription factors in inflammatory pathways, we examined the effects of WG on PMACI-stimulated degradation of IKB- $\alpha$ and phosphorylation of IKK. As shown in Figure 6B, PMACI induced the phosphorylation of IKK and degradation of IKB $\alpha$; however, WG pretreatment suppressed the PMACI-induced activation of IKK and IKB $\alpha$ in HMC-1 cells. These results indicated that the inhibition of MAPK and NF- $\mathrm{KB}$ signaling pathways is involved in WG's mechanisms in PMACI-induced allergic inflammatory responses in HMC-1 cells. 
A

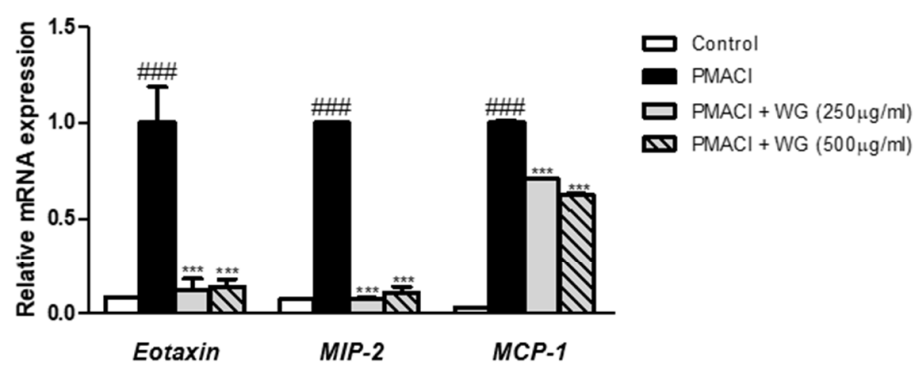

B

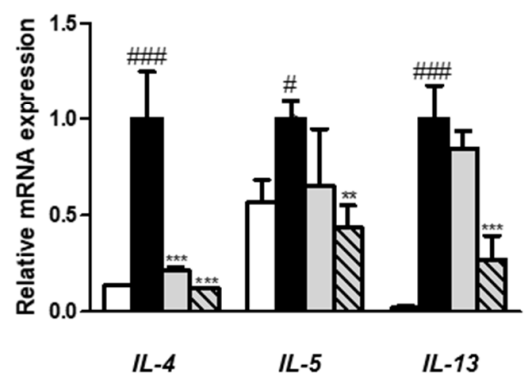

C

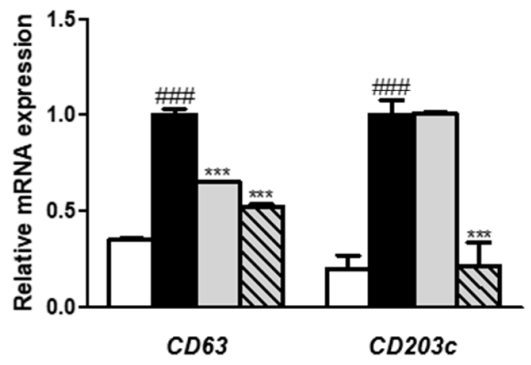

Figure 5. Effects of WG on the chemokine, $\mathrm{CD}$ antigens, and Th2 cytokines in PMACI-stimulated HMC-1 cells. Total RNA prepared from HMC-1 cells, while the mRNA levels of (A) Eotaxin, MIP-2, MCP-1, (B) CD63, CD203c, and (C) IL-4, IL-5, IL-13 were determined by quantitative qRT-PCR. The data shown represent means \pm S.D. of three independent experiments. Note: ${ }^{\#} p<0.05,{ }^{\# \# \#} p<0.001$ vs. the control group; ${ }^{* *} p<0.01,{ }^{* * *} p<0.001$ vs. PMACI-treated group.

A

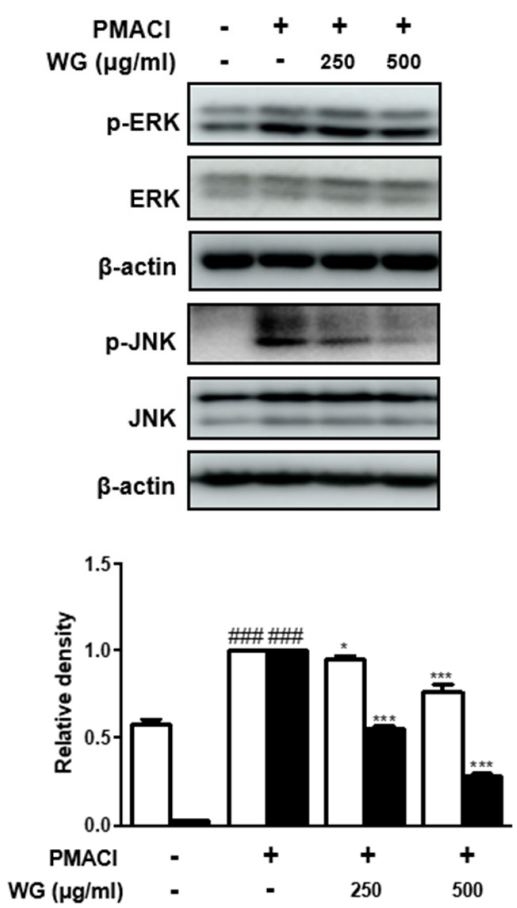

B
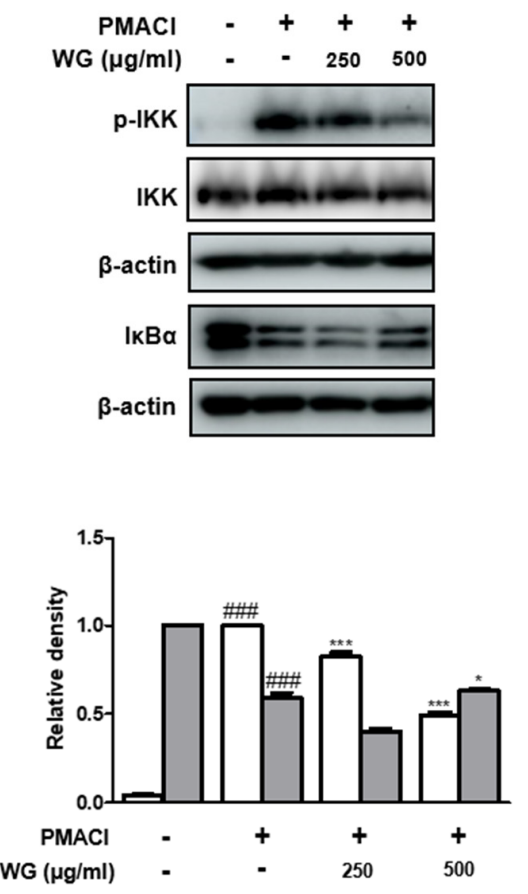

Figure 6. Effects of WG on PMACI-induced activation of MAPKs and NF- $\mathrm{kB}$ signaling pathway in PMACI-stimulated HMC-1 cells. Western blot analysis was performed using total proteins and specific antibodies for (A) ERK, JNK, (B) IKK, and IKB $\alpha$. Here, $\beta$-actin was used to normalize protein expression levels. Densitometric analysis was performed using Bio-Rad Quantity One ${ }^{\circledR}$ Software. The data shown represent means \pm S.D. of three independent experiments. Note: ${ }^{\# \#} p<0.001$ vs. the control group; ${ }^{*} p<0.05,{ }^{* * *} p<0.001$ vs. PMACI-treated group. 


\section{Discussion}

Licorice and its constituents have been reported to have antiallergic and anti-inflammatory activities [24,25]. Therefore, investigating WG to verify whether it has the previously reported pharmacological activities found in existing licorice varieties is as important as developing novel varieties to utilize WG. The antiallergic effects of this study support the promising activities of WG. In the present study, we investigated the inhibitory effects of WG on mast-cell-mediated allergic inflammation. IgE-mediated allergic reactions through the FceRI receptor are known to be the main mechanism of mast cell activation and systemic anaphylaxis [26]. Thus, we evaluated whether WG inhibits mast cell degranulation using a compound-48/80-induced mouse model of anaphylaxis and histamine-releasing cells, such as rat basophilic leukemia RBL-2H3 and human mast cell line HMC-1 cells. WG treatment delayed mortality in anaphylactic events due to systemic mast cell degranulation. The administration of WG had a better effect than the positive control DSCG treatment group (Figure 1A). Moreover, we found that the release of preformed mediator histamine expression in both mast cell types was reduced by WG treatment (Figure 3). This correlates with the decrease in serum IgE levels after WG treatment in the mouse model of anaphylaxis (Figure 1B). As a mast cell stimulator, compound 48/80 causes alterations in intracellular calcium influx as well as cyclic adenosine monophosphate (cAMP) levels, consequently causing allergic reactions, including IgE synthesis, mast cell degranulation, and histamine release $[27,28]$. The mast cells activated by compound $48 / 80$ exert host defense, sensitization to antigen, and proinflammatory functions through the release of mediators such as cytokines, chemokines, leukotrienes, and tryptase proteases, as well as histamine $[27,29]$. These mediators can promote Th2 cell differentiation and class switching into $\mathrm{IgE}$ in B cells [30]. While the serum levels of $\mathrm{IgE}$ in circulation are very low, elevated total $\operatorname{IgE}$ levels indicate that an allergic reaction is in progress. The increased level of $\operatorname{IgE}$ induced by compound $48 / 80$ reflected systemic anaphylaxis, which is a form of immediate hypersensitivity. However, this systemic allergic reaction was inhibited by DSCG and WG in this study. DSCG inhibits extracellular calcium influx and degranulation of mast cells, subsequently preventing the release of histamine and mediator allergic inflammatory reactions [31]. Furthermore, our results showed that WG decreased the expression of Th2 cytokines such as IL-4 and IL-13, which are required for IgE synthesis (Figure 5B). The results were in agreement with the previous report that DSCG selectively inhibited IL-4 and spontaneous IgE production by B cells [32]. It is supposed that WG also alleviates allergic reaction induced by compound $48 / 80$ through blocking IgE synthesis, mast cell degranulation, and histamine release via a similar preventive mechanism to DSCG.

In response to allergies, a diverse range of immunologic messengers, such as calcium, induce the biosynthesis or release of proinflammatory cytokines and chemokines in mast cells [33]. The present study found that WG suppressed TNF- $\alpha$ and IL-6 in both mast cells and anaphylaxis mouse models, suggesting that WG can regulate mast-cell-mediated allergic inflammatory responses. In line with this, WG downregulated the expression of chemokines, such as eotaxin, MIP-2, and MCP-1, as well as the expression of Th2 cytokines (IL-4, IL-5, and IL-13) in PMACI-stimulated HMC-1 cells (Figure 5). These results are supported by previous reports showing that the main constituents, glycyrrhizin and licorice flavonoids, inhibit the expression levels of eotaxin, MIPs, MCP-1, TNF- $\alpha$, and IL-6 in lipopolysaccharide-stimulated RAW264.7 cells [34] and downregulate MCP-1 and MIP-2 expression in cerulein-stimulated pancreatic acinar cells [35]. The expression of cell surface markers CD63 and CD203c was also inhibited by WG in PMACI-stimulated HMC1 cells (Figure 5), supporting the antiallergic effects of WG on markers of anaphylactic degranulation [36]. Furthermore, the production of proinflammatory cytokines, which are involved in allergic inflammation, is primarily controlled by the MAPK and NF- $\mathrm{kB}$ signaling pathways that are involved in allergic inflammation [37]. We also found that the inhibitory effect of WG was associated with decreased activation of not only the NF- $\mathrm{kB}$ pathway but also the parallel MAPK ERK/JNK signaling cascade upon stimulation with PMACI (Figure 6). Therefore, the results indicated that WG inhibited allergic responses in 
HMC-1 cells by suppressing the expression of chemokines, Th2 cytokines, and CD antigens and regulating the MAPK/NF- $\mathrm{KB}$ signaling pathway.

In present study, WG had no toxicity up to $1000 \mu \mathrm{g} / \mathrm{mL}$ in both human mast cell HMC-1 and rat basophil RBL-2H3 cell lines (Figure 3A). In the general toxicity test, the no observed adverse effect level (NOAEL) of WG was higher than $5000 \mathrm{mg} / \mathrm{kg} /$ day, and no target organs were identified in rats [1]. Moreover, $1400 \mu \mathrm{g} / \mathrm{mL}$ WG did not induce genotoxic or mutagenic activities in the in vitro chromosome aberration test [2]. Therefore, WG exerts its antiallergic inflammatory activities without any side effects caused by toxicity, although studies on the metabolism process of WG in the human body are required. Recent reports described that glycyrrhizin, $18 \beta$-glycyrrhetinic acid, and liquiritigenin isolated from G. glabra relieved the IgE-induced allergic response [5]. When licorice is administered orally, glycyrrhizin, a triterpene glycoside, is transformed to $18 \beta$-glycyrrhetinic acid in the digestive tract by gut microbiota [38] and is then absorbed along with liquiritigenin into the blood. Thus, the use of licorice for oral administration has more advantages in regulating degranulation and cytokine production in mast cells, which cause allergic disease. Wongam has a $3.96 \%$ glycyrrhizin content, which is much higher than that of G. uralensis (1.90\%) [39]; therefore, we expect that novel Glycyrrhiza varieties will have more effective pharmacological activities than existing Glycyrrhiza species. Nevertheless, further investigations are necessary to elucidate the actions of specific components and their targets in WG, and this study suggests that WG can potentially be used to treat allergic inflammatory responses by inhibiting mast cell activation. Here, we provided evidence for the contribution of WG to the treatment or prevention of mast-cell-mediated allergic inflammatory diseases.

\section{Conclusions}

In conclusion, WG exhibited beneficial effects against mast-cell-mediated allergic inflammatory responses through the inhibition of histamine release, IgE production, allergyrelated cytokines, and chemokines. Our study demonstrated the mechanisms responsible for the antiallergic and inflammatory effects of WG, which suppresses the MAPK/NF- $\mathrm{KB}$ signaling pathway. Considering the obtained results that WG exerts antiallergic inflammatory activity, WG may be a potential alternative therapeutic agent in the management of allergic diseases.

Author Contributions: Conceptualization, H.-J.A.; resources, J.L. and J.-S.J.; investigation, Y.-M.K.; data curation, W.K., J.-H.L. and J.L.; writing-original draft preparation, Y.-M.K.; writing-review and editing, J.L., W.K., J.-H.L. and J.-S.J.; visualization, Y.-M.K.; funding acquisition, J.L. and J.-S.J.; supervision, H.-J.A. All authors have read and agreed to the published version of the manuscript.

Funding: This work was carried out with the support of the "Cooperative Research Program for Agriculture Science and Technology Development Project (No. PJ01424602)" administered by the Rural Development Administration of the Republic of Korea.

Institutional Review Board Statement: All procedures were performed in accordance with the university guidelines and approved by the Ethical Committee for Animal Care and the Use of Laboratory Animals, Korean Medicine, Sangji University (Wonju, South Korea; approval no. 2019-10).

Informed Consent Statement: Not applicable.

Data Availability Statement: Datasets used or analyzed in the current study are available from the corresponding author on reasonable request.

Conflicts of Interest: The authors declare that they have no competing interest. 


\begin{abstract}
Abbreviations
IgE, immunoglobulin E; FceRI, high-affinity IgE receptor; Th, T helper; IL, interleukin; MIP-2, macrophage inflammatory protein-2; MCP-1, monocyte chemoattractant protein-1; MAPK, mitogenactivated protein kinase; ERK, extracellular signal-regulated kinase; JNK, c-Jun N-terminal kinase; NF- $k B$, nuclear factor- $\kappa B$; IKK, IкB kinase; IкB, inhibitor of NF- $\kappa B$.
\end{abstract}

\title{
References
}

1. Kim, D.-G.; Lee, J.; Kim, W.; An, H.-J.; Lee, J.-H.; Chang, J.; Kang, S.-H.; Song, Y.-J.; Jeon, Y.-D.; Jin, J.-S. Assessment of General Toxicity of the Glycyrrhiza New Variety Extract in Rats. Plants 2021, 10, 1126. [CrossRef] [PubMed]

2. Song, Y.-J.; Kim, D.-G.; Lee, J.; Kim, W.; An, H.-J.; Lee, J.-H.; Jeon, Y.-D.; Chang, J.; Kang, S.-H.; Soh, J.-R.; et al. In Vitro Genotoxicity Assessment from the Glycyrrhiza New Variety Extract. Appl. Sci. 2021, 11, 10257. [CrossRef]

3. Kang, S.-H.; Song, Y.-J.; Jeon, Y.-D.; Kim, D.-K.; Park, J.-H.; Soh, J.-R.; Lee, J.-H.; Kitalong, C.; Kim, W.; An, H.-J.; et al. Comparative Study of Anti-Inflammatory Effect on DSS-Induced Ulcerative Colitis Between Novel Glycyrrhiza Variety and Official Compendia. Appl. Sci. 2021, 11, 1545. [CrossRef]

4. Pastorino, G.; Cornara, L.; Soares, S.; Rodrigues, F.; Oliveira, M.B.P. Liquorice (Glycyrrhiza glabra): A phytochemical and pharmacological review. Phytother. Res. 2018, 32, 2323-2339. [CrossRef] [PubMed]

5. Shin, Y.-W.; Bae, E.-A.; Lee, B.; Lee, S.H.; Kim, J.A.; Kim, Y.-S.; Kim, D.-H. In Vitro and In Vivo Antiallergic Effects of Glycyrrhiza glabra and Its Components. Planta Med. 2007, 73, 257-261. [CrossRef]

6. Yang, R.; Yuan, B.-C.; Ma, Y.-S.; Zhou, S.; Liu, Y. The anti-inflammatory activity of licorice, a widely used Chinese herb. Pharm. Biol. 2016, 55, 5-18. [CrossRef] [PubMed]

7. Kim, S.-H.; Hong, J.-H.; Lee, J.-E.; Lee, Y.-C. 18ß-Glycyrrhetinic acid, the major bioactive component of Glycyrrhizae Radix, attenuates airway inflammation by modulating Th2 cytokines, GATA-3, STAT6, and Foxp3 transcription factors in an asthmatic mouse model. Environ. Toxicol. Pharmacol. 2017, 52, 99-113. [CrossRef] [PubMed]

8. Fiore, C.; Eisenhut, M.; Krausse, R.; Ragazzi, E.; Pellati, D.; Armanini, D.; Bielenberg, J. Antiviral effects of Glycyrrhiza species. Phytother. Res. 2008, 22, 141-148. [CrossRef]

9. Dong, S.; Inoue, A.; Zhu, Y.; Tanji, M.; Kiyama, R. Activation of rapid signaling pathways and the subsequent transcriptional regulation for the proliferation of breast cancer MCF-7 cells by the treatment with an extract of Glycyrrhiza glabra root. Food Chem. Toxicol. 2007, 45, 2470-2478. [CrossRef]

10. Wang, W.; Hu, X.; Zhao, Z.; Liu, P.; Hu, Y.; Zhou, J.; Zhou, D.; Wang, Z.; Guo, D.; Guo, H. Antidepressant-like effects of liquiritin and isoliquiritin from Glycyrrhiza uralensis in the forced swimming test and tail suspension test in mice. Prog. Neuro-Psychopharmacol. Biol. Psychiatry 2008, 32, 1179-1184. [CrossRef]

11. Pawankar, R. Allergic diseases and asthma: A global public health concern and a call to action. World Allergy Organ. J. 2014, 7, 1-12. [CrossRef] [PubMed]

12. Altrichter, S.; Kriehuber, E.; Moser, J.; Valenta, R.; Kopp, T.; Stingl, G. Serum IgE Autoantibodies Target Keratinocytes in Patients with Atopic Dermatitis. J. Investig. Dermatol. 2008, 128, 2232-2239. [CrossRef] [PubMed]

13. Wang, Q.; Lepus, C.M.; Raghu, H.; Reber, L.L.; Tsai, M.M.; Wong, H.H.; von Kaeppler, E.; Lingampalli, N.; Bloom, M.S.; $\mathrm{Hu}, \mathrm{N}$; ; et al. IgE-mediated mast cell activation promotes inflammation and cartilage destruction in osteoarthritis. Elife 2019, 8, e39905. [CrossRef]

14. Corry, D.B.; Kheradmand, F. Induction and regulation of the IgE response. Nature 1999, 402, 18-23. [CrossRef]

15. Kraft, S.; Jouvin, M.H.; Kulkarni, N.; Kissing, S.; Morgan, E.S.; Dvorak, A.M.; Schroder, B.; Saftig, P.; Kinet, J.P. The tetraspanin $\mathrm{CD}_{63}$ is required for efficient IgE-mediated mast cell degranulation and anaphylaxis. J. Immunol. 2013, 191, 2871-2878. [CrossRef] [PubMed]

16. Metcalfe, D.D.; Pawankar, R.; Ackerman, S.J.; Akin, C.; Clayton, F.; Falcone, F.H.; Gleich, G.J.; Irani, A.-M.; Johansson, M.W.; Klion, A.D.; et al. Biomarkers of the involvement of mast cells, basophils and eosinophils in asthma and allergic diseases. World Allergy Organ. J. 2016, 9, 7. [CrossRef] [PubMed]

17. Vantur, R.; Rihar, M.; Koren, A.; Rijavec, M.; Kopac, P.; Bidovec-Stojkovic, U.; Erzen, R.; Korosec, P. Chemokines during anaphylaxis: The importance of CCL2 and CCL2-dependent chemotactic activity for basophils. Clin. Transl. Allergy 2020, 10, 1-11. [CrossRef] [PubMed]

18. Song, E.-H.; Chung, K.-S.; Kang, Y.-M.; Lee, J.-H.; Lee, M.; An, H.-J. Eupatilin suppresses the allergic inflammatory response in vitro and in vivo. Phytomedicine 2018, 42, 1-8. [CrossRef]

19. Yang, E.-J.; Song, I.-S.; Song, K.-S. Ethanol extract of Glycyrrhizae Radix modulates the responses of antigen-specific splenocytes in experimental autoimmune encephalomyelitis. Phytomedicine 2019, 54, 56-65. [CrossRef]

20. Yamamura, Y.; Santa, T.; Kotaki, H.; Uchino, K.; Sawada, Y.; Iga, T. Administration-Route Dependency of Absorption of Glycyrrhizin in Rats: Intraperitoneal Administration Dramatically Enhanced Bioavailability. Biol. Pharm. Bull. 1995, 18, 337-341. [CrossRef]

21. Lloyd, C. Chemokines in allergic lung inflammation. Immunology 2002, 105, 144-154. [CrossRef] [PubMed]

22. Castan, L.; Magnan, A.; Bouchaud, G. Chemokine receptors in allergic diseases. Allergy 2016, 72, 682-690. [CrossRef] [PubMed] 
23. MacGlashan, D. Expression of CD203c and CD63 in human basophils: Relationship to differential regulation of piecemeal and anaphylactic degranulation processes. Clin. Exp. Allergy 2010, 40, 1365-1377. [CrossRef]

24. Han, S.; Sun, L.; He, F.; Che, H. Anti-allergic activity of glycyrrhizic acid on IgE-mediated allergic reaction by regulation of allergy-related immune cells. Sci. Rep. 2017, 7, 7222. [CrossRef] [PubMed]

25. Shin, E.M.; Zhou, H.Y.; Guo, L.Y.; Kim, J.A.; Lee, S.H.; Merfort, I.; Kang, S.S.; Kim, H.S.; Kim, S.; Kim, Y.S. Anti-inflammatory effects of glycyrol isolated from Glycyrrhiza uralensis in LPS-stimulated RAW264.7 macrophages. Int. Immunopharmacol. 2008, 8 , 1524-1532. [CrossRef]

26. Krystel-Whittemore, M.; Dileepan, K.N.; Wood, J.G. Mast Cell: A Multi-Functional Master Cell. Front. Immunol. 2016, 6, 620. [CrossRef] [PubMed]

27. Matsui, N.; Ito, D.; Takabatake, Y.; Nashioka, E.; Tada, S.; Kanagawa, M.; Fukuishi, N.; Akagi, M. Compound 48/80, a Mast Cell Stimulator, Enhances Synthesis of IgE and IgG Induced by Intranasal Application of Ovalbumin in Mice. Biol. Pharm. Bull. 2015, 38, 1954-1959. [CrossRef] [PubMed]

28. Rothschild, A.M. Mechanisms of histamine release by compound 48/80. Br. J. Pharmacol. 1970, 38, 253-262. [CrossRef]

29. Amin, K. The role of mast cells in allergic inflammation. Respir. Med. 2012, 106, 9-14. [CrossRef] [PubMed]

30. Galli, S.J.; Tsai, M. IgE and mast cells in allergic disease. Nat. Med. 2012, 18, 693-704. [CrossRef]

31. Norris, A.A. Pharmacology of sodium cromoglycate. Clin. Exp. Allergy 1996, 26, 5-7. [CrossRef] [PubMed]

32. Kimata, H.; Yoshida, A.; Ishioka, C.; Mikawa, H. Disodium cromoglycate (DSCG) selectively inhibits IgE production and enhances IgG4 production by human B cell in vitro. Clin. Exp. Immunol. 1991, 84, 395-399. [PubMed]

33. Kang, J.A.; Song, H.-Y.; Byun, E.-H.; Ahn, N.-G.; Kim, H.-M.; Nam, Y.R.; Lee, G.H.; Jang, B.-S.; Choi, D.S.; Lee, D.-E. Gammairradiated black ginseng extract inhibits mast cell degranulation and suppresses atopic dermatitis-like skin lesions in mice. Food Chem. Toxicol. 2018, 111, 133-143. [CrossRef] [PubMed]

34. Liu, Z.; Zhong, J.-Y.; Gao, E.-N.; Yang, H. Effects of glycyrrhizin acid and licorice flavonoids on LPS-induced cytokines expression in macrophage. China J. Chin. Mater. Med. 2014, 39, 3841-3845.

35. Panahi, Y.; Fakhari, S.; Mohammadi, M.; Rahmani, M.R.; Hakhamaneshi, M.S.; Jalili, A. Glycyrrhizin down-regulates CCL2 and CXCL2 expression in cerulein-stimulated pancreatic acinar cells. Am. J. Clin. Exp. Immunol. 2015, 4, 1-6. [PubMed]

36. Hemmings, O.; Kwok, M.; McKendry, R.; Santos, A.F. Basophil Activation Test: Old and New Applications in Allergy. Curr. Allergy Asthma Rep. 2018, 18, 1-12. [CrossRef]

37. Lee, M.; Lee, N.Y.; Chung, K.S.; Cheon, S.Y.; Lee, K.T.; An, H.J. Roxatidine attenuates mast cell-mediated allergic inflammation via inhibition of NF-kappaB and p38 MAPK activation. Sci. Rep. 2017, 7, 41721. [CrossRef]

38. Kim, D.-H.; Hong, S.-W.; Kim, B.-T.; Bae, E.-A.; Park, H.-Y.; Han, M.J. Biotransformation of glycyrrhizin by human intestinal bacteria and its relation to biological activities. Arch. Pharmacal Res. 2000, 23, 172-177. [CrossRef]

39. National Institute of Horticultural and Herbal Science, Rural Development Administration. Available online: https: / / www.nihhs.go.kr/viewer/sn_skin/doc.html?fn=42CD191439E9A9C32A42FDA1361266\&rs=/viewer/result/ (accessed on 16 November 2021). 